\title{
ON THE INHIBITION OF THE REACTION BETWEEN ANODIC ALUMINUM OXIDE AND WATER
}

\author{
J. M. SANZ, J. M. ALBELLA and J. M. MARTÍNEZ-DUART \\ Departmento de Fisica Aplicada \& Instituto de Fisica del Estado Sólido (C.S.I.C.), \\ Universidad Autonóma de Madrid, Cantoblanco (Madrid), Spain
}

(Received November 1, 1978; in final form April 11, 1979)

\begin{abstract}
The reaction between anodic aluminum oxide and several passivating solutions of citric acid and ammonium dihydrogen phosphate (ADP) is studied by capacitance measurements. In addition, the passivating effect of the abcve solutions has been evaluated by the reaction of the oxide with pure boiling water and subsequent anodization. The results show a strong passivating effect of the ADP solution which is partially diminished by the addition of citrate ions.
\end{abstract}

\section{INTRODUCTION}

The reaction between anodic aluminum oxide and water has been widely studied by Hunter et al., ${ }^{1}$ Bernard and Randall ${ }^{2}$ and Vermilyea and Vedder. ${ }^{3}$ It has been suggested from these investigations that the mechanism of this reaction should be very similar to that between aluminum and water since the kinetics of growth of the hydroxide is similar in both cases. Vedder and Vermilyea ${ }^{4}$ have proposed the following steps for the reaction between aluminum and water: (i) formation of an amorphous oxide, (ii) solution of the oxide, and (iii) precipitation of the aluminum hydroxide. Therefore, in the reaction between aluminum oxide and water it should be expected that only steps (ii) and (iii) will occur.

Vermilyea and Vedder ${ }^{3}$ have also studied several factors, such as kind of electrolyte, its $\mathrm{pH}$, etc., which influence the reaction between aluminum oxide and water. They have found that the presence of $\mathrm{PO}_{4}^{3-}$ ions, even in small concentrations, strongly inhibits the attack of the oxide by the water (step ii). This fact is attributed to the formation of a complex of phosphorus and aluminum, known as variscite, nonsoluble in water and strongly bound to the aluminum surface.

In this paper some of the aspects of the inhibition caused by $\mathrm{NH}_{4} \mathrm{H}_{2} \mathrm{PO}_{4}$ in the reaction between anodic aluminum oxide and boiling water are examined. The incorporation of the $\mathrm{PO}_{4}^{3-}$ ions on the aluminum surface has been carried out by immersing the oxidized aluminum foil in an aqueous solution of the monobasic phosphate at a temperature of $90^{\circ} \mathrm{C}$. The rate of the reaction has been studied for different phosphate concentrations and also for varying amounts of citric acid added to a solution of a given phosphate concentration.

The significance of the reaction between aluminum oxide and water in the presence of phosphate ions is considerable since it is well known that during the manufacture of electrolytic capacitors it is a usual practice to soak the oxidized aluminum foil in a hot aqueous solution containing $\mathrm{PO}_{4}^{3-}$ ions in order to increase the oxide's stability. ${ }^{5,6}$

\section{EXPERIMENTAL}

The aluminum foil employed in this work has been of the type used in the manufacture of the anodes of electrolytic capacitors, with a purity of $99.99 \%$. The foil was supplied electrochemically etched, with a surface gain of about 16 . Samples of $3 \times 3 \mathrm{~cm}^{2}$ were cut and anodized at a constant current of $30 \mathrm{~mA}$ $\mathrm{cm}^{-2}$ (projected area). After reaching $400 \mathrm{~V}$ the samples were left in the electrolytic cell until the current diminished to $1 / 100$ of its initial value. The anodization was carried out at $90^{\circ} \mathrm{C}$ in an aqueous solution of boric acid and ammonium pentaborate with a resistivity of $1200 \mathrm{ohm} \mathrm{cm}$. In order to increase the rate of the voltage rise during the anodization, the aluminum foil was previously immersed in boiling deionized water $(\rho>1 \mathrm{Mohm} . \mathrm{cm})$ for five minutes. By this procedure the increase of voltage with time is approximately linear ${ }^{7}$ with a rate of about $50 \mathrm{~V} \mathrm{~min}^{-1}$ in this case. After the first anodization, the samples were hydrated and oxidized again following exactly the same procedure. In this 
way the oxide is more stable resulting in a more reproducible capacitance measurement.

Previous to the study of the reaction between aluminum oxide and water, the anodized samples were soaked for five minutes in an aqueous solution of several concentrations of $\mathrm{NH}_{4} \mathrm{H}_{2} \mathrm{PO}_{4}$ at $90^{\circ} \mathrm{C}$ and also, in some cases, in a $2 \%$ solution of this electrolyte containing different amounts of citric acid. It has been verified in our laboratory that a five-minute immersion is enough to get the surface of the foil saturated with the phosphate complex, except in the case of the lowest concentration investigated $(0.002 \%)$. After this treatment, the samples were made to react with deionized boiling water for about one hour.

After each of the above steps of oxidations and hydrations, the capacitance and dielectric losses of the samples were measured at $100 \mathrm{~Hz}$ by a HewlettPackard 4261 A bridge in an electrolyte of boric acid (5\%) and ammonium hydroxide with a resistivity of $100 \mathrm{ohm} \mathrm{cm}$. Although the treatment of the oxide above room temperature produces a change in its dielectric constant accompanied by a decrease in capacitance, ${ }^{3}$ Bernard and Randall ${ }^{2}$ have shown that the value of $1 / \mathrm{C}$, with the proper corrections, can be used as a measure of the thickness of the oxide.

\section{RESULTS AND DISCUSSION}

Figure 1 shows the fraction of oxide attacked during the 5 min immersion in the hot ADP solution as a function of the $\mathrm{pH}$ of the solution (curve a). Since it was observed that the dielectric constant at $90^{\circ} \mathrm{C}$ is about $95 \%$ of its value at room temperature, the capacitance measurements were corrected accordingly. From Figure 1 it can be noted that the amount of the oxide attacked by the ADP electrolyte is relatively small until a $\mathrm{pH}$ of about 5 is reached. The amount then increases abruptly. The point in Figure 1 labelled as 'water' corresponds to the value obtained when the sample, after anodising, is treated for $5 \mathrm{~min}$ in pure water at $90^{\circ} \mathrm{C}$. An aqueous solution of citric acid also produces a similar decrease in the oxide's attack in relation to water (curve b), although the effect appears at lower values of $\mathrm{pH}$. It can be inferred from this result that a small amount of citric acid produces a moderating effect in the reaction between aluminum and water. In this respect, it is interesting to point out that the citric acid is well known for its inhibiting capability for the formation of bohemite during hydration of aluminum. ${ }^{8}$ The above results are in contrast with those obtained when increasing amounts of citric acid are added to a $2 \%$ solution of $\mathrm{NH}_{4} \mathrm{H}_{2} \mathrm{PO}_{4}(\mathrm{pH}=4.3)$. In this case the rate of attack increases as the $\mathrm{pH}$ decreases (curve c). Curves (a) and (c) both show the effect of the $\mathrm{pH}$ in the rate of attack of the electrolyte based upon $\mathrm{PO}_{4}^{3-}$ ions, showing a minimum for a value of the $\mathrm{pH}$ in the range between 4 and 5 . A similar effect has also been observed by Vermilyea and Vedder ${ }^{3}$ who attribute it to the presence of hydroxide on the surface and also to the lower solubility of aluminum compounds.

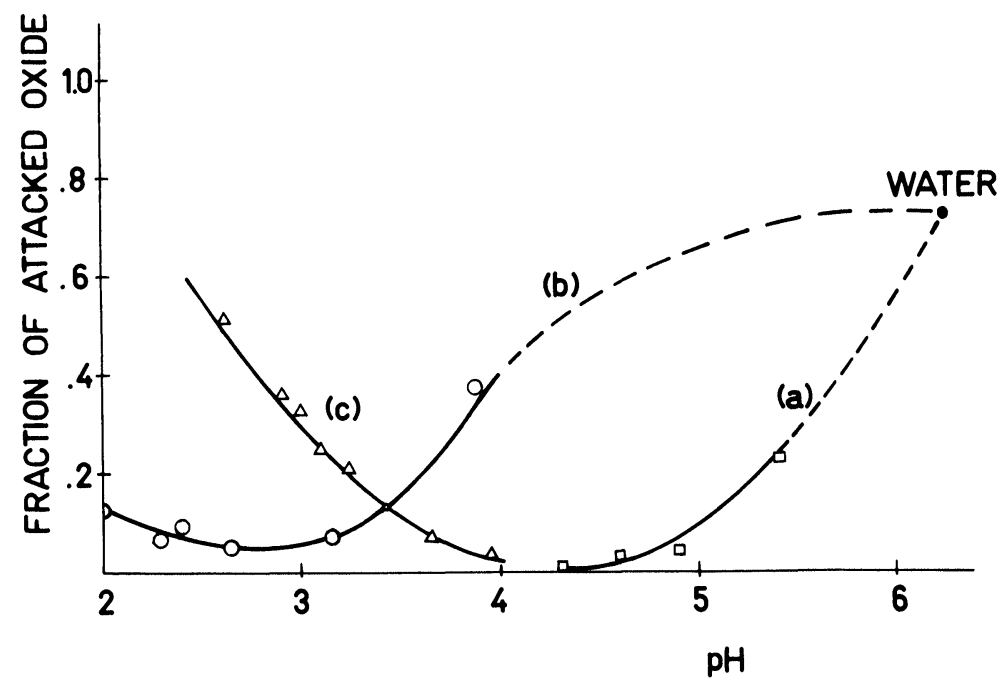

FIGURE 1 Fraction of attacked oxide during immersion in several solutions as a function of the $\mathrm{pH}$ of the solution. Curve a: ammonium dihydrogen phosphate; curve $\mathrm{b}$ : citric acid; curve c: citric acid added to a solution of $2 \%$ ammonium dihydrogen phosphate in water. 


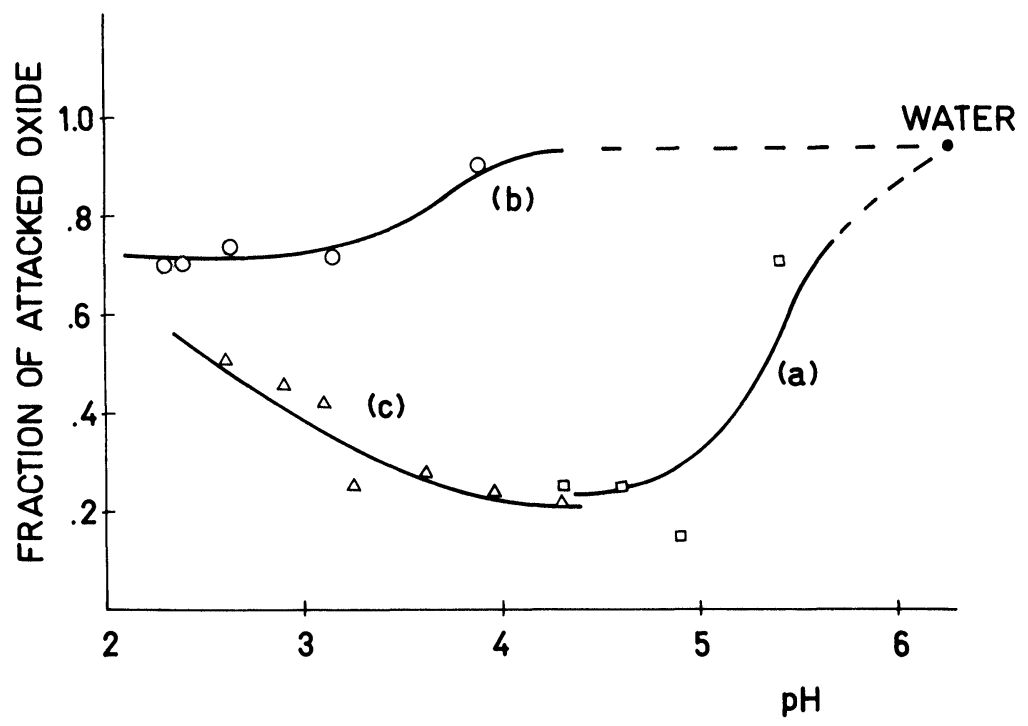

FIGURE 2 Fraction of attacked oxide during the immersion in pure boiling water (1 hour) of samples passivated by immersion in the solutions specified in Figure 1, as a function of the pH of these solutions.

Figure 2 shows the fraction of oxide attacked (with reference to the state of the oxide after anodising) in the 1 -hour reaction with deionized boiling water for samples which had been soaked in the ammonium phosphate and citric acid electrolytes. The passivating effect of the ADP solution can be clearly appreciated from curve (a) and it may be attributed to the presence of phosphorus on the surface. ${ }^{3}$ Auger electron spectroscopy measurements carried out in our laboratory confirm this assumption. The presence of the citrate ion in the ADP solution in increasing amounts rapidly diminishes the passivating capability of the electrolyte as can be observed from curve (c). The citrate ion by itself does not exert any passivating effect since in this case (curve b) the percentage of oxide removed is very similar to the case in which the samples are not treated or only immersed in hot water.

The above results are in agreement with those obtained from the reoxidation curves of the samples after having reacted with the boiling water. Figure 3 shows for some of the samples the variation of the voltage during the reoxidation at a constant current $\left(8 \mathrm{~mA} \mathrm{~cm}{ }^{-2}\right)$ and in the same electrolyte of the first anodization. It can be observed that the rate of voltage increase is much faster for the samples treated in a $2 \%$ ADP solution (curve A) than for those treated in the same salt at a lower concentration (curve D), as well as for those soaked in an aqueous solution of citric acid (curves $\mathrm{E}$ and $\mathrm{F}$ ) or simply in pure water (curve G). The lower oxidation rate (zone I) that occurs in a sample treated in water, for example, can be attributed to the slow diffusion of the electrolyte across the porous structure of the hydroxide and to the filling of voids in the oxide as proposed by Alwitt and Dyer. ${ }^{9}$ Once the electrolyte has penetrated the hydroxide and the voids become filled with new layers of oxide, the rate of anodization increases (zone II) due to the direct transformation of hydroxide into oxide or to some other currentconsuming transformation in the oxide. ${ }^{7}$ Subsequently, the rate of anodization becomes slow again (zone III), and it may be due to the formation of new layers of oxide which had been attacked in the reaction with water. ${ }^{9}$ This interpretation is supported by the fact that the rate of voltage increase, $25 \mathrm{~V}$ $\min ^{-1}$, is not too different from the value during the first anodization of aluminum. In agreement with this interpretation, the samples treated in citric acid (curves $\mathrm{E}$ and $\mathrm{F}$ ) show the formation of less quantity of hydroxide and a greater oxide attack than those that were only immersed in water. The samples treated in a low ADP concentration ( $0.004 \%$, curve D) still show a lesser amount of hydroxide and a smaller attack by the electrolyte, whereas those samples soaked in a $2 \% \mathrm{ADP}$ concentration (curve A) present a very fast voltage rise which indicates that practically no hydroxide has been formed and that the oxide has not been attacked by the electrolyte. Finally, when citric acid is added to the preceding ADP solution no hydroxide seems to be formed in the reaction with water. However, the oxide is attacked more 


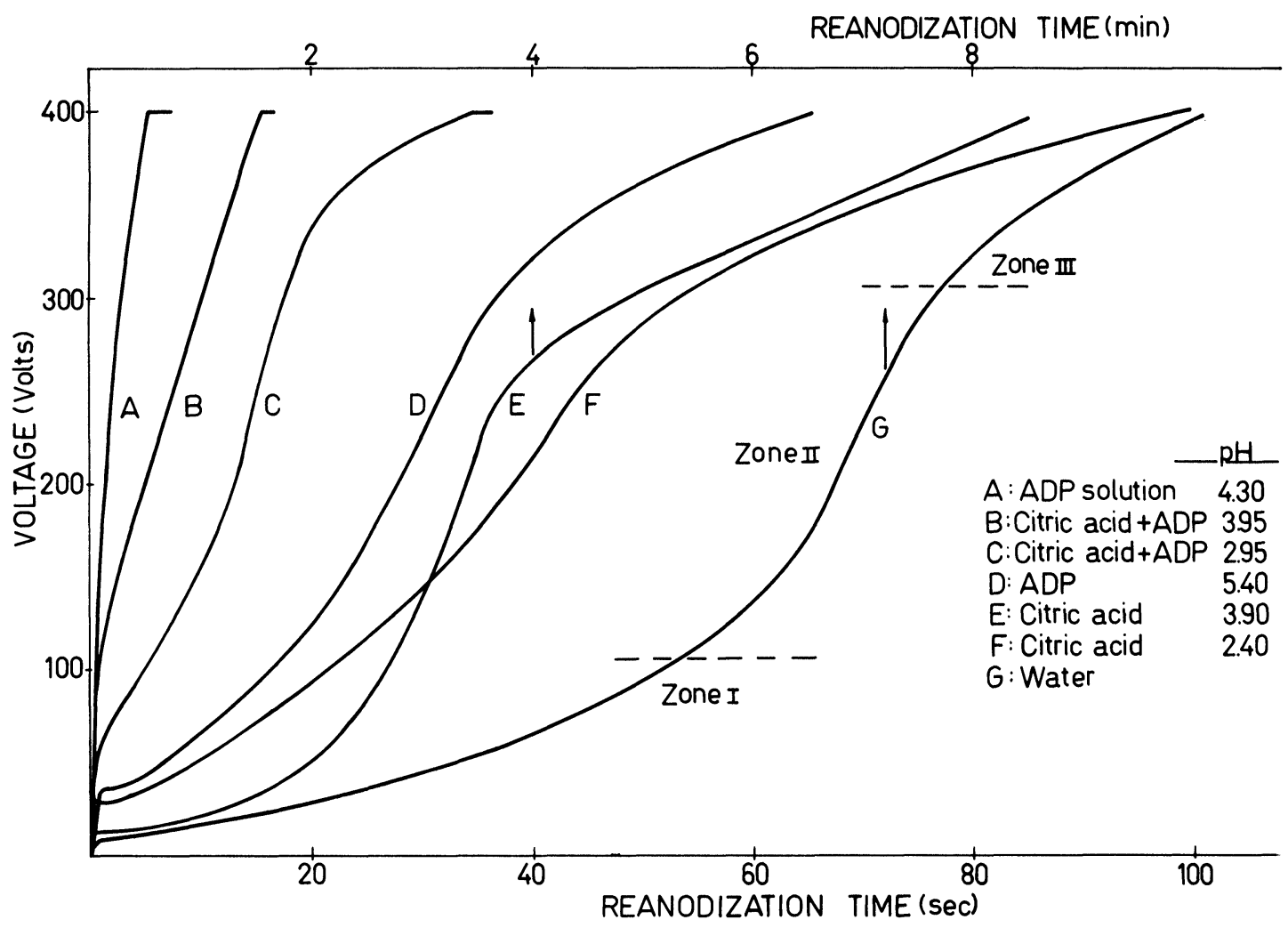

FIGURE 3 Reanodization curves for passivated samples after the reaction with boiling water.

and more as the citric acid concentration increases (compare curves $\mathrm{B}$ and $\mathrm{C}$ with curve $\mathrm{A}$ in zone III).

The conclusion that can be established from this work is than an immersion in an aqueous solution of ADP exerts a truly passivating effect on the aluminum oxide surface, inhibiting its reaction with water. The presence of citric acid in the above solution decreases its passivating effect giving rise to an attack of the oxide's surface with the formation of small amounts of aluminum hydroxide. Finally, the treatment in a citric acid solution causes the formation of some hydroxide (less than would form in water) and an attack to the oxide's surface. It is difficult at this moment to give a more detailed explanation of these results. For this, it would be necessary to carry out a more profound study in order to elucidate the mechanisms of the reaction between aluminum oxide and water in the presence of the combined action of ions such as the phosphate and citrate ions.

\section{ACKNOWLEDGEMENTS}

We would like to thank Bianchi S.A. (San Sebastian, Spain) for the partial support of this work.

\section{REFERENCES}

1. M. S. Hunter, P. F. Towner and D. L. Robinson, Hydration of anodic oxide films, Proc. Amer. Electroplaters Soc. 46th Ann. Conf., 3, 220 (1959).

2. W. J. Bernard and J. J. Randall, The reaction between anodic aluminum and water, J. Electrochem. Soc., 108, 822 (1961).

3. D. A. Vermilyea and W. Vedder, Inhibition of the aluminum + water reaction, Trans. Faraday Soc., 66, 2644 (1970).

4. W. Vedder and D. A. Vermilyea, Aluminum + water reaction, Trans. Faraday Soc., 65, 561 (1969).

5. G. Aurouze and R. Buttoudin, Verfahren zur Chemischen behandlung von aluminiumfolien für electrolytische kondensatoren, German Patent No. 1.925 .914 (1970).

6. P. M. Vogel and J. H. Hofman, Verfahren zur behandlung von aluminiumfolie fur elektroly tkondensatore, German Patent No. 2.238.245 (1973).

7. R. S. Alwitt, A. J. Breen and J. S. Leach, The transformation of hydrous aluminum oxide during anodic oxidation, Proc. Symp. Oxide-Electrolytes Interfaces, Electrochem. Soc., Princeton (1973).

8. D. Altempohl, Untersuchungen uber die reaktion zwischen aluminium und wasser, Aluminium, 33, 78 (1957).

9. R. S. Alwitt and C. K. Dyer, Electrical instability of composite aluminum oxide films, Electrochim. Acta, 23, 355 (1978). 

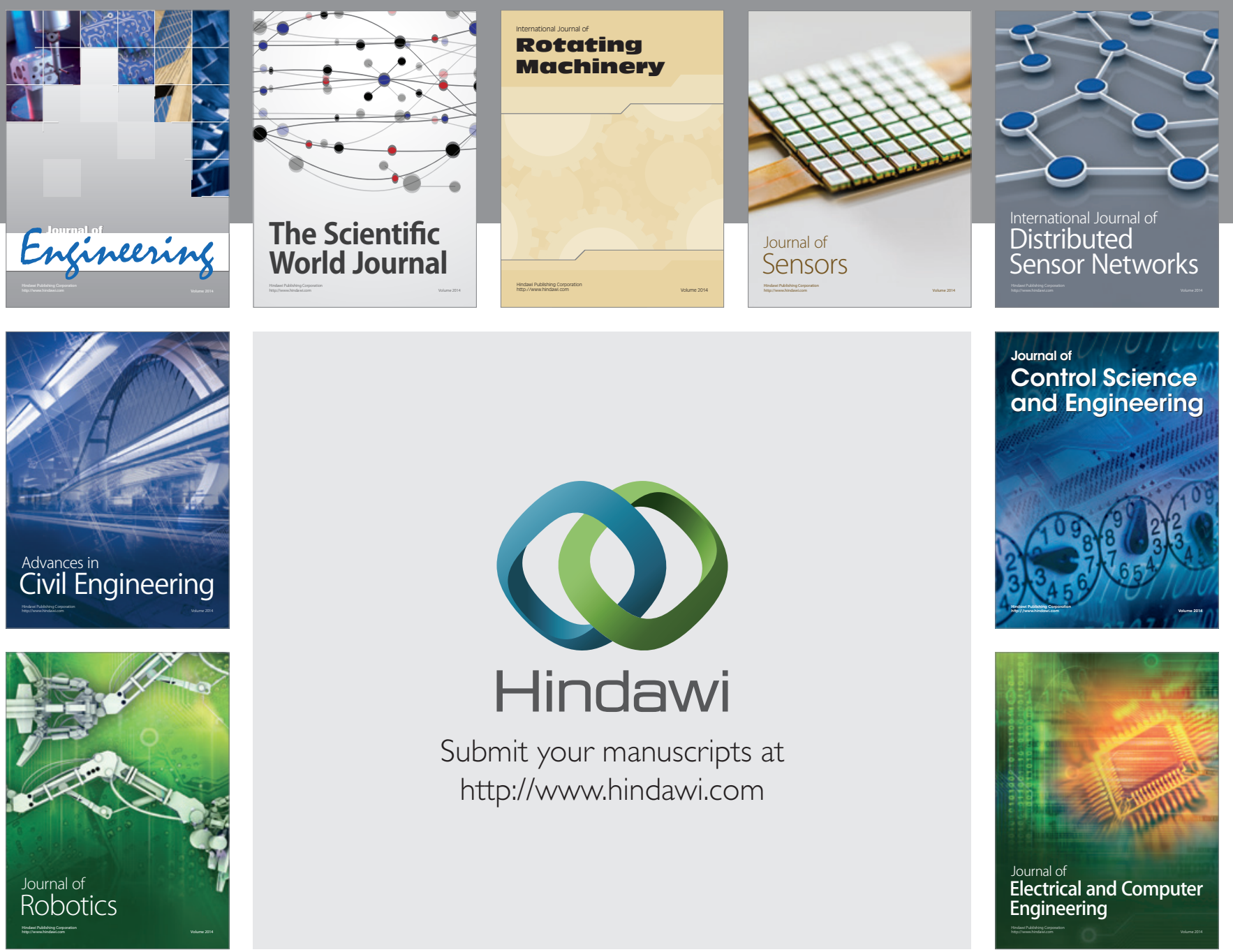

Submit your manuscripts at

http://www.hindawi.com
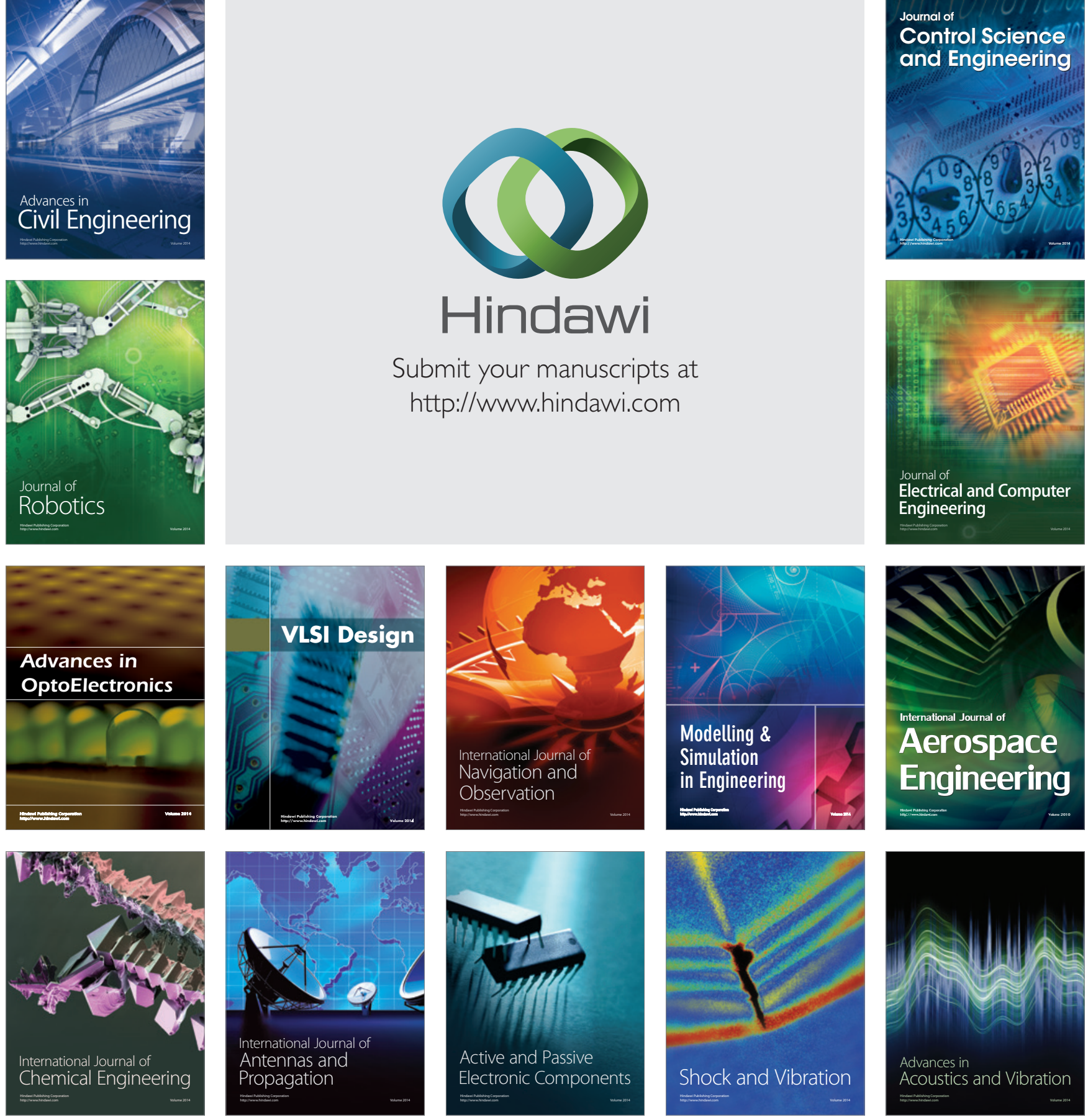